Sarah E. Rollens

\title{
Framing Social Criticism in the Jesus Movement
}

The Ideological Project in the Sayings Gospel Q

[Die Bildung der Gesellschaftskritik in der Jesus-Bewegung. Der ideologische Entwurf in der Logienquelle Q.]

Veröffentlicht auf Englisch.

Obwohl es immer populärer wird, den Ursprung der frühesten ländlichen Jesus-Bewegung im bäuerlichen Milieu zu sehen, haben die Befürworter dieser Theorie bisher nicht die Implikationen der Tatsache untersucht, dass das älteste Zeugnis diese Bewegung ein höchst stilisiertes Schriftstück ist. Im Gegenteil, die Logienquelle Q, ein anspruchsvoller Text mit Ähnlichkeiten zu anderen antiken Schriften und sogar dokumentarischen Papyri, scheint kein Produkt aus bäuerlichem Umfeld zu sein. Dennoch scheint Q auch kein Produkt der Eliten zu sein, denn der Text ist voller Tropen zu sozialen und ökonomischen Grenzlagen. Um Zugang zur schwer fassbaren »mittleren Gesellschaftsschicht« zu erhalten, aus der die Verfasser von Q möglicherweise stammen, untersucht Sarah E. Rollens Kulturen übergreifend Figuren aus dem Mittelstand, um das ideologische Vorhaben in Q zu verstehen.

Sarah E. Rollens Born 1984; 2006 BA in Philosophy \& Religion and Sociology; 2008 MA in Religious Studies; 2013 PhD in Religious Studies; currently an instructor in the Department of Religious Studies at the University of Alabama.

Jetzt bestellen:

https://mohrsiebeck.com/buch/framing-social-criticism-in-the-jesus-movement-9783161535239?no_cache=1 order@mohrsiebeck.com

Telefon: $+49(0) 7071-923-17$

Telefax: +49 (0)7071-51104 